\title{
As metáforas animais e suas implicações interacionais
}

\author{
Fernanda Cavalcanti* \\ Ana Cristina Pelosi**
}

\begin{abstract}
Resumo
Objetivamos com este artigo discutir as implicações das metáforas animais na linguagem diária dos falantes com base nas hipóteses da inexpressividade, da compacidade e da nitidez formuladas por Gibbs (1994) e no papel social das metáforas em Rodriguez (2009). Para tanto, além da introdução e da conclusão, o artigo foi organizado em três seções. Na primeira seção, discutimos o papel das metáforas verbais na comunicação humana em Gibbs (1994); na segunda seção, a metáfora animal SER HUMANO É ANIMAL; e na terceira seção, a relevância das metáforas animais na compreensão e construção das identidades sociais e de gênero em Rodriguez (2009) bem como analisamos, a título de exemplo das questões levantadas, a metáfora animal 'perua' a partir de posts publicados no blog Saltimbanca e no site Na Casa da Gabi.

Palavras-chave: Metáfora verbal. Metáfora animal. Gênero e identidades sociais. Linguagem diária. Interações verbais.
\end{abstract}

\section{Introdução}

- Você acredita que o homem possa ser representado por um animal? Qual seria? Por qual razão?

- Não vejo nada de errado nisso, além do mais já é consenso pegar características peculiares de alguns animais e representá-las ficcionalmente, como 'a mãe coruja protetora', 'a cobra venenosa e traiçoeira', 'a potranca gostosona', 'o jacaré comilão' ou 'o delicado veadinho', que fazem parte da cultura popular.

A resposta à pergunta acima formulada foi retirada dos dados coletados pela primeira autora por meio da aplicação de cinco questionários por ocasião de sua pesquisa de doutoramento, na qual trabalhamos com o processo de conceptualização da expressão convencional 'cabra' à luz da Teoria dos Modelos Cognitivos.

* Professora adjunta do Departamento de Linguística da UERJ e pós-doutoranda da UFMG.

** Professora associada da UFC e professora visitante da UNISC. 
Com efeito, o questionário no qual consta a pergunta acima reproduzida foi respondido por 30 jovens universitários e adultos brasileiros, residentes em Fortaleza, no ano de 2013. Importante ressaltar que 60,0\% dos 30 participantes responderam afirmativamente à pergunta, ao passo que 30,0\% responderam de maneira negativa à mesma pergunta, $6,7 \%$ não souberam respondê-la e 3,3\% não a responderam. De acordo com esses dados, seria plausível afirmar que os respondentes reconhecem a ocorrência do processo de conceptualização do homem em temos de animal ou, ainda, de metáforas animais em nosso sistema conceptual.

As metáforas animais são avaliadas por Kövecses (2010) como o terceiro domínio-fonte mais produtivo das Metáforas Conceptuais presentes em nosso sistema conceptual. Nessa perspectiva, tal autor estima que, além de boa parte do comportamento humano parecer ser compreendido em termos de comportamento animal, isto é, pela Metáfora Conceptual COMPORTAMENTO HUMANO É COMPORTAMENTO ANIMAL (doravante, MC COMPORTAMENTO HUMANO É COMPORTAMENTO ANIMAL), pessoas seriam igualmente conceptualizadas em termos de animais, isto é, pela MC SER HUMANO É ANIMAL, a exemplo de expressões em português: 'A jararaca chegou'; 'Não sei como ela se casou com aquele cavalo batizado'; 'Ele é um verme'; 'A vaca da minha chefe não veio hoje'.

Kövecses (2010) pondera ainda que, apesar de grande parte das metáforas animais parecerem mapear características negativas dos seres humanos, algumas dentre elas não o fariam, a exemplo de MULHER SEXY É GATINHA.

Por outro lado, de acordo com Gibbs (1994), a linguagem figurada ou ainda as metáforas verbais são dominantes na comunicação cotidiana, sobretudo porque, além de elas se constituírem em principal recurso para expressão verbal humana, permitiriam que os usuários elaborassem suas ideias da maneira mais eficiente, compacta e nítida, facilitando, assim, as interações verbais nas quais se encontrariam engajados. Além disso, segundo Rodriguez (2009), as metáforas animais teriam forte influência na compreensão e construção de identidades sociais e de gênero, a exemplo das metáforas animais relativas à conceptualização da mulher e de sua condição social nas línguas de tradição inglesa e espanhola.

Nessa perspectiva, objetivamos, com este artigo, discutir as metáforas animais e suas implicações nas interações verbais. Para tanto, organizamos nossa discussão a partir de três seções, além da conclusão e introdução. Na primeira seção, tratamos do papel das metáforas verbais na comunicação humana a partir de Gibbs 
(1994); na segunda seção, abordamos o procedimento cognitivo de metaforização SER HUMANO É ANIMAL; na terceira seção, baseando-nos em Rodriguez (2009), discutimos a relevância das metáforas animais para a compreensão e construção de identidades sociais e de gênero bem como analisamos, a título de exemplo das questões levantadas, a metáfora animal 'perua', que aparece em posts publicados no blog Saltimbanca e no site Na Casa da Gabi.

\section{As metáforas verbais no âmbito da comunicação}

Em seu livro The Poetics of Mind, Gibbs apresenta vastos corpora nos quais é possível comprovar a predominância de linguagem figurada na comunicação diária entre as pessoas. Embora Gibbs (1994) pondere que nem todas as interações verbais sejam de natureza metafórica, menciona a realização de estudos que revelaram, de um lado, que a produção de autores americanos, entre os períodos de 1675 a 1975, contava com a presença maciça de metáforas relacionadas a domínios conceituais como racionalidade, emoção e significado da vida; e, de outro lado, que havia ocorrência relevante de linguagem figurada em contextos especializados ou específicos, como no âmbito das sessões de psicoterapia e dos ensaios e debates entre Nixon e Kennedy.

Ademais, com base em resultados de estudos realizados com o simples intuito de verificar com que frequência se emprega a linguagem figurada em conversas do dia a dia, Gibbs (1994) afirma que os falantes usam 1,80 novas metáforas verbais por minuto e 4,08 metáforas verbais cristalizadas por minuto. Dessa forma, ele chega a um resultado final segundo o qual, considerando que os falantes entabulam conversa em ao menos duas horas por dia, um falante proferiria 4,7 milhões de novas metáforas contra 21,4 milhões de metáforas cristalizadas ao longo de 60 anos de vida.

Em assim sendo, Gibbs (1994) argumenta que a ubiquidade da linguagem figurada nas interações verbais se constituiria em evidência de que a língua seria primordialmente moldada por linguagem desse tipo. Diante de tal evidência, para tal autor e demais teóricos da Metáfora Conceptual, a linguagem figurada seria uma instanciação de recursos cognitivos basilares - as Metáforas Conceptuais que desempenhariam, no âmbito de nosso sistema conceptual, o papel de formar conceitos, de motivar a mudança semântica e o significado das expressões linguísticas. Em outras palavras, para os teóricos da Metáfora Conceptual, as 
Metáforas Conceptuais influenciariam na maneira como as pessoas significam boa parte das palavras e expressões verbais.

Diante de tal contundência, e à luz da Teoria da Metáfora Conceptual, doravante TMC, Gibbs (1994) conclui que, ao contrário do que Aristóteles postula em sua Poética, não seriam apenas as pessoas talentosas e de inteligência superior que fariam uso privilegiado da metáfora, mas os usuários comuns da língua, para realizar atos de linguagem tanto em comunicação diária como em comunicação especializada. Com o intuito de fornecer ferramentas de análise do papel das metáforas no âmbito da comunicação cotidiana ou ainda da linguagem em uso, Gibbs (1994) formula as hipóteses da inexpressividade, da compacidade e da nitidez.

A hipótese da inexpressividade diz respeito ao fato de a linguagem figurada fornecer recursos aos usuários da língua para expressar ideias e pensamentos de forma mais eficiente quando não única, a exemplo da metáfora animal 'João empacou nessa pergunta'. De acordo com a hipótese de inexpressividade, tal metáfora evidenciaria a não adequação da linguagem literal para expressar de forma eficiente a ideia de João não conseguir avançar em suas tarefas.

A hipótese da compacidade atenta para o fato de que a linguagem figurada permitiria aos usuários da língua condensar e compactar ideias e pensamentos ricos e complexos em expressões linguísticas, a exemplo da metáfora animal 'sua fidelidade é canina'. Tal metáfora condensaria, grosso modo, a ideia de que uma pessoa nutre em relação a alguém sentimento sólido e forte de respeito, admiração e amor, que lhe será, por isso, sempre fiel. Por outro lado, as unidades discretas da linguagem literal, cuja função maior seria a de abordar o real de forma rigorosa e precisa, não ofereceriam aos usuários da língua recursos adequados para expressar a riqueza de informações condensadas e compactadas na expressão 'fidelidade canina', a não ser de forma prolixa e recorrente.

A hipótese da nitidez trata da questão de que os usuários da língua conseguem produzir junto aos seus interlocutores imagens mais ricas, mais nítidas e mais detalhadas de suas ideias e pensamentos quando fazem uso de metáforas como no caso da ideia de uma 'fidelidade canina'. Dificilmente, os usuários da língua conseguiriam tal efeito se tentassem fazê-lo por meio das unidades discretas da linguagem literal, cujo pendor é a busca da construção de ideias e pensamentos pautados pela exatidão, pela lógica e pela informatividade. 
Por outro lado, ao postular o caráter conceptual das metáforas, Lakoff (1993) estabelece distinção entre tais recursos e palavras e expressões. Justifica que as Metáforas Conceptuais seriam mapeamentos compreendendo domínios conceptuais fonte e alvo, que, ao se tornarem convencionalizados, emergem na linguagem por meio de conceitos e significados compartilhados pelas palavras e expressões. Tal visão faz Lakoff (1993) declarar que o pensamento e o raciocínio estariam primordialmente no foco da TMC; e que a linguagem ocuparia um papel secundário nas análises a serem promovidas à luz da teoria em questão. Gibbs (1994), contudo, inverte a prioridade de foco postulada por Lakoff (1993), ao estabelecer como objetivo, a análise da Metáfora Conceptual a partir de uma abordagem pragmática em vez de uma abordagem voltada marcadamente para o funcionamento do sistema conceptual humano.

Com a mudança de enfoque acima proposta por Gibbs (1994), a discussão a respeito da Metáfora Conceptual se instala também no âmbito da língua em uso e da pragmática, já que, com isso, o autor em questão fornece ferramentas para os analistas que buscam problematizar as implicações das metáforas no âmbito das interações verbais.

\section{Metáforas animais}

AMC PESSOAS SÃO ANIMAIS, de acordo comKövecses (2005), seria um procedimento cognitivo bastante produtivo e primevo. Ainda segundo Kövecses (2005), para o arqueólogo cognitivo Steve Mithen, o desenvolvimento do pensamento metafórico teria aparecido no período do Paleolítico Superior, conforme sugeririam os desenhos feitos em cavernas mostrando homens em forma de animais. Ou seja, datariam desse período evidências de que a comunicação humana se realizaria a partir do cruzamento entre os vários domínios cognitivos. Diante de tal hipótese, Kövecses (2005) considera que as metáforas animais representariam para os estudos a respeito da cognição humana, recursos com característica particularmente interessante, já que forneceriam a base cognitiva e metafórica para conhecidos e antigos processos antropológicos, como o totemismo.

Nessa perspectiva, em sua obra intitulada Metaphor: a practical introduction, Kövecses refina seu entendimento sobre a MC PESSOAS SÃO ANIMAIS, ao situá-la no sistema de metáforas da Grande Cadeia do Ser e ao considerá-la de natureza congruente. Tal sistema metafórico seria responsável pela conceptualização de 
objetos - entidades conceptuais que têm estabilidade no espaço e no tempo e que na linguagem emergem como categorias que funcionam como nomes - em especial da conceptualização do ser humano e de seu comportamento em termos de animais.

Com efeito, tal sistema, segundo Lakoff e Turner (1989), teria como base o modelo cultural A Grande Cadeia do Ser, de tradição, sobretudo, judaico-cristã, mas presente em várias culturas. Nesse sistema, ser humano, animal, plantas e objetos se encontram hierarquicamente relacionados, situando-se o ser humano no topo da escala, seguido dos animais, das plantas e dos objetos. Dessa forma, ainda de acordo com Lakoff e Turner (1989), o ser humano é definido a partir de atributos de alta ordem e comportamento (i. e. pensamento e personalidade); os animais são definidos a partir de atributos instintivos e comportamento; as plantas são definidas a partir de atributos biológicos e comportamento; e os objetos são definidos a partir de atributos físicos e naturais e de comportamento físico e natural.

A partir da organização dos quatro níveis, seria possível estabelecer a compreensão de um determinado nível dessa hierarquia em função de outro nível, tornando tal sistema de caráter metafórico. Ou seja, tal processo de metaforização pode se dar do domínio-fonte baixo para o domínio-alvo alto, a exemplo de quando o ser humano é compreendido metaforicamente em termos de animal ou objeto inanimado; ou do domínio-fonte alto para o domínio-alvo baixo a exemplo de quando os objetos são compreendidos em termos de ser humano, no chamado processo de personificação.

Nessa perspectiva, Kövecses (2010) reforça mais uma vez que o processo de conceptualização do homem e de seu comportamento em termos de animal e de comportamento animal é um dos mais recorrentes no âmbito do sistema de metáforas da Grande Cadeia do Ser e, por conseguinte, no sistema conceptual humano. Tal ênfase tem como base não apenas a hipótese de desenvolvimento do pensamento metafórico de Mithen, como também o levantamento por ele realizado junto aos vários dicionários de metáforas e às listas das metáforas mais comuns, a exemplo de Master Metaphor List, e às pesquisas realizadas por estudiosos da TMC.

Ademais, Kövecses (2010) pondera que as MCs PESSOAS SÃo ANIMAIS e COMPORTAMENTO HUMANO É COMPORTAMENTO ANIMAL motivariam, de modo geral, conceitos de caráter negativo, a exemplo, em português, de expressões como: 'Ela foi uma vaca comigo'; 'Isso é trairagem'; 'Ele berrou bem alto'; 'As mulheres ficam cacarejando na cozinha'. Contudo, propõe que as metáforas animais seriam de caráter congruente, de modo que a MC HUMANO É ANIMAL teria caráter mais 
geral, neutro e universal do que as metáforas PESSOAS SÃO ANIMAIS, PESSOAS ABJETAS SÃO ANIMAIS E COMPORTAMENTO HUMANO INDESEJÁVEL É COMPORTAMENTO ANIMAL, qUe teriam, por sua vez, caráter mais específico e cultural.

Em suma, as metáforas animais, na condição de linguagem figurada, além de se constituírem em recursos relevantes para a comunicação, segundo as hipóteses formuladas por Gibbs (1994), seriam recorrentes nas várias e diferentes línguas naturais, já que se constituem em recursos conceptuais de natureza primeva, universal e contundentemente produtiva.

\section{0 papel social das metáforas animais}

Segundo Kövecses (2005), a metáfora é um fenômeno linguístico, conceptual, sociocultural, neural e corpóreo. Esse autor afirma ainda que foi preciso que ocorressem algumas revoluções para que os estudiosos do assunto reconhecessem essas várias facetas da metáfora. Nessa perspectiva, Rodriguez (2009) argumenta contra o caráter neutro ou, ainda, marcadamente universalista das metáforas.

Ao defender que as metáforas sofrem influências de componentes comportamentais e ideológicos, Rodriguez (2009) advoga que as metáforas animais seriam exemplos de metáforas que projetam experiências relativas à construção de identidades sociais e de gêneros. Assinala, assim, que muitas dessas metáforas formulam e motivam conceitos a respeito da condição feminina, a exemplo da conceptualização de mulher como gata, pomba, franga ou cadela nas línguas inglesa e espanhola.

Com efeito, Rodriguez (2009) ressalta o caráter negativo das conceptualizações de mulher em termos de animal, ao considerar que tais metáforas seriam motivadas por crenças e valores de determinado grupo de indivíduos, representado pelo macho branco e heterossexual, que, ao se constituir em cânone social, estabelece determinados grupos de indivíduos, a exemplo das mulheres, como marginais. Em outras palavras, Rodriguez (2009) considera que as metáforas PESSOAS SÃO ANIMAIS seriam recursos cognitivos que projetariam conceitos depreciativos a respeito das mulheres e demais grupos de indivíduos, como os dos imigrantes, que contrariam a ordem canônica representada por grupo de indivíduo representado pelo macho branco heterossexual.

Baseado na relação entre o potencial sexual das mulheres e o potencial de comestibilidade dos animais, bem como de seu porte, Rodriguez (2009) analisa 
as metáforas animais que conceptualizam a condição feminina nas comunidades de língua espanhola e inglesa. Assim, propõe que as metáforas animais sejam classificadas, grosso modo, a partir de três grupos: (1) metáfora animal e a mulher como animal doméstico, cujo potencial comestível não seria autorizado, e a relação sexual seria considerada espúria; (2) metáfora animal e a mulher como animal domesticado, cujo tamanho e o grau de domesticidade ao variar, provocaria variação quanto a ser o potencial sexual dessa mulher autorizado ou não; (3) metáfora animal e a mulher como animal selvagem, cujo potencial sexual não seria reconhecido, já que seu potencial de comestibilidade não o seria.

Com base nessa relação, a autora aponta para exemplos da conceptualização de mulher como animal doméstico com base na ideia de uma mulher cadela, isto é, de uma mulher conceptualizada como prostituta ou feia; com base na ideia de uma mulher gata, isto é, de uma mulher conceptualizada como maliciosa, perdida ou prostituta. A autora ainda cita exemplos de metáforas relacionadas com pássaros de pequeno porte como o canário e o periquito, com os quais se conceptualiza mulher como jovem. Ainda sobre as metáforas animais com pássaro, Rodriguez (2009) pondera que pássaro em espanhol tem conotação sexual e que determinados usos das metáforas animais com canário e periquito em inglês se referem ao coletivo de mulheres jovens e desfrutáveis, de acordo com o jargão dos universitários americanos.

Se pensarmos na relação dessas metáforas com a língua portuguesa do Brasil, afirmaríamos, de maneira impressionista, que as metáforas com cadela trazem conotações similares àquelas elencadas por Rodriguez (2009). Contudo, gata estaria relacionada à conceptualização de uma mulher jovem e bonita, com alguma ressalva para a expressão nordestina 'gato véi', que traz conotações relativas a uma mulher prostituta e feia. Quanto às metáforas relacionadas com periquito, teríamos exemplos que se referem à genitália feminina, utilizada, sobretudo em linguagem infantil. Metáforas relacionadas a canário se referem a mulheres muito jovens, cujo uso é, a nosso ver, marcadamente literário e poético.

Rodriguez (2009) considera cadela como exemplo prototípico de metáforas animais que conceptualizam a condição social feminina. Ou seja, para a autora, tal metáfora mapeia aspectos negativos e ofensivos em relação às mulheres, já que o ser humano, ao desenvolver relação de afeto com tal animal, não reconheceria o potencial de comestibilidade do animal em questão. Consequentemente, seu potencial sexual é proibido ou considerado espúrio. 
Quanto às metáforas animais relacionadas a animais domesticados, Rodriguez (2009) aponta, sobretudo, para os animais cuja função é a de servir ou de alimentar o ser humano e, dependendo de seu tamanho, teriam seu potencial sexual autorizado ou não. No caso de animais de grande porte, ela analisa metáforas relacionadas à vaca, à égua e à mula, cujo potencial sexual não seria autorizado, e assim as metáforas com esses animais estariam mapeando aspectos negativos femininos como gordura, feiura e estupidez. Contudo em relação aos animais de pequeno porte como a galinha, a franga, a pomba e a perua, seu potencial sexual seria autorizado, mapeando, assim, aspectos associados à fragilidade e ao frescor femininos.

No caso da língua portuguesa do Brasil, ao que parece, à exceção da galinha, constante em metáforas animais que apontam para promiscuidade feminina, os demais animais estão sendo mapeados em relação à condição social feminina de forma similar.

Finalmente, quanto à conceptualização da condição feminina em termos de animais selvagens, tais como a loba, a tigresa e a baleia, segundo Rodriguez (2009), o mapeamento estaria salientando traços femininos ora relacionados à promiscuidade feminina, ora a sua gordura. De acordo com a categorização proposta pela autora, esses animais são de grande porte, apresentam baixo grau de domesticidade e baixa capacidade de alimentação humana, tendo, dessa forma, seu potencial sexual obscuro.

Para concluir, Rodriguez (2009) afirma que, além de possuírem base cognitiva, as metáforas animais apresentam motivação sociocultural, tendo em vista que elas projetam atitudes e crenças de determinadas comunidades em relação não apenas a determinados animais, mas em relação a determinados animais em termos de determinados grupos sociais. Ela acrescenta, ainda, que essa dimensão sociocultural das metáforas animais as torna importantes veículos para transmissão e perpetuação de crenças sociais em benefício de determinadas práticas discursivas, sobretudo, das comunidades linguísticas por ela estudadas. Ou seja, os usuários das línguas inglesa e espanhola, ao fazerem uso de metáforas animais para conceptualizar a condição social feminina, transmitiriam e perpetuariam crenças sociais segundo as quais as mulheres integrariam o grupo de indivíduos considerados socialmente marginais ou inferiores.

A título de ilustração acerca do que debatemos neste artigo, analisamos o seguinte trecho de uma postagem intitulada "O Direito de Ser Perua. Ou não", 
publicada no blog A Saltimbanca: “A minha perua sempre esteve lá desde que eu era pequena, por mais que eu queira culpar meus pais por isso (...) sei que não ia colar". Com base, nessa postagem, consideramos 'minha perua' como uma instanciação de uma metáfora animal que conceptualiza a condição feminina, tendo em vista que, segundo a autora, 'ser perua' é algo que define o gênero feminino.

Em conformidade com o que discutimos mais acima, os atributos 'doméstico' e 'de pequeno porte' de animais como a perua têm sido mapeados em termos de mulher frágil, dotada de frescor e sexualmente interessante. Para analisarmos melhor o mapeamento desses atributos, lançamos mão de outra postagem intitulada "Ser Perua É", publicada no blog Na Casa da Gabi, na qual sua autora afirma que "Ser Perua É":

(i) Usar a hora do almoço para ir ao salão. Sentar na cadeira e tomar um cappuccino light glamoroso.

(ii) Ler a revista ELLE.

(iii) Colocar os pés de molho numa bacia com água morninha e perfumada e bolinhas de gude massageadoras no fundo.

(iv) Esticar o pezinho para a pedicure e relaxar.

(v) Ouvir a fofoca alheia enquanto uma profissional transforma seu pé cascudo num templo de podofilia.

(vi) Escolher um esmalte tomatinho, para ficar bem ousado e moderno.

(vii) Se espreguiçar na cadeira e deixar seu celular cair na bacia de água que já não está tão morninha nem tão perfumada.

(viii) Tentar desesperadamente secar o referido celular com a toalha da manicure;

(ix) Tentar secar o celular com um secador de cabelos.

(x) Arrancar a bateria com os dentes e tentar secar a bateria na sua saia.

(xi) Perceber que seu celular morreu para sempre.Sentar de novo na cadeira com ar blasé.

(xii) Borrar as unhas enquanto levanta correndo porque seu horário de Almoço acabou.

(xiii) Ligar para VIVO e perguntar se eles não querem te dar um aparelho novo de graça.

(O direito de ser perua. Ou não. Disponível em: <www. soltandoosverbos. blogspot.com $>$. Acesso em: 8 mar. 2013.)

De acordo com tal postagem, podemos afirmar que a mulher é conceptualizada como vaidosa, mundana, preocupada e adepta das últimas tendências da moda; procura ser sofisticada e moderna; é desastrada, atrasada, consumista, não tão esperta, mas petulante. Dessa forma, é possível relacionar o conjunto de atributos 
como vaidosa, mundana, procurar ser sofisticada com a tentativa de uma mulher buscar se tornar bonita, agradável, sedutora, jovem, desejável, palatável, isto é, sexualmente interessante.

Ademais, o conjunto de atributos 'atrasada', 'desastrada' e 'pouco esperta' é mapeado em termos de fragilidade ou, ainda, de animal de pequeno porte - tal qual Rodriguez (2009) avalia as metáforas relacionadas a animais como franga, pomba e perua. Ou seja, a perua demonstra fragilidade por ser animal doméstico e de pequeno porte, de um lado, e por ser uma mulher que não administra de maneira adequada seus recursos intelectuais e sua relação com o tempo e o espaço.

Nessa perspectiva, ao usar a linguagem figurada, 'minha perua', em seu blog, A Saltimbanca atualiza uma metáfora animal segundo a qual a condição feminina é conceptualizada com base na ideia de uma mulher frágil, desprotegida e com potencial sexual aflorado e autorizado. Ou seja, a autora atualiza, assim, uma visão a respeito da condição social feminina de acordo com crenças e valores hegemônicos para os quais tal condição é, sobretudo, avaliada segundo seu potencial sexual. E, no caso da metáfora animal perua, tal potencial é autorizado, tendo em vista que o animal em questão é mapeado em termos de fragilidade e frescor.

Além disso, A Saltimbanca conseguiria, por meio dessa metáfora, estabelecer com seu público uma comunicação mais eficiente, de acordo com as hipóteses postuladas por Gibbs (1994). Ou seja, de acordo com as hipóteses de inexpressividade, de compacidade e de nitidez, a ideia construída a partir da metáfora animal em questão não poderia ser mais bem expressa, ou não poderia ser expressa de outra maneira, tendo em vista que tal ideia apresenta de forma compacta e clara crenças e valores que se tem acerca da mulher e do animal em questão na comunidade de língua portuguesa do Brasil.

Interessante ressaltar que o atributo 'pouco esperta' ou mesmo 'estúpida' teria sido mapeado nas metáforas animais relativas à perua discutidas por Rodriguez (2009), tendo em vista que tal animal é considerado pouco inteligente nas comunidades espanhola e inglesa. É possível verificar que esse atributo é também mapeado na comunidade de língua portuguesa do Brasil, sobretudo, se pensarmos na expressão idiomática 'bancar o (ou servir de) peru' em jogos/brincadeiras ou mesmo na vida.

Em outras palavras, a partir de um sistema de mapeamento de atributos salientes tanto na mulher como na perua, a metáfora verbal ou linguagem 
figurada 'perua' é licenciada e possibilita uma interação mais eficiente por ser sociocultural e historicamente situada, já que atualiza valores e crenças compartilhados pelos membros da cultura brasileira. Dessa forma, consideramos que a abordagem das metáforas animais proposta por Rodriguez (2009) assim como as três hipóteses formuladas por Gibbs (1994) levantam questões relevantes no que diz respeito às funções comunicativas das metáforas, especialmente das metáforas animais. Pois, se, de um lado, tais metáforas são consideradas como recursos que permitem a expressão mais eficiente de ideias e pensamentos nas interações verbais realizadas pelos falantes, de outro lado, são consideradas como recursos que projetam e repercutem crenças e valores de determinados grupos socialmente hegemônicos, isto é, são dispositivos cognitivos socioculturalmente situados.

\section{Considerações finais}

Conforme já assinalado, o objetivo deste artigo foi o de discutir as implicações das metáforas animais nas interações verbais. Dessa forma, lançamos mão das três hipóteses formuladas por Gibbs (1994) acerca da função comunicativa da linguagem figurada e da visão de Rodriguez (2009) sobre o papel social das metáforas animais na construção das identidades sociais e de gênero, especialmente da condição feminina nas tradições de língua inglesa e espanhola.

Nessa perspectiva, consideramos que a TMC pode oferecer contribuições importantes não somente para a discussão sobre a cognição humana e o sistema conceitual humano postuladas por Lakoff (1993), mas também para a discussão no âmbito das interações verbais e das práticas sociodiscursivas. $\mathrm{Ou}$ seja, do ponto de vista pragmático, a TMC pode contribuir para as questões que digam respeito à função comunicativa da linguagem figurada, sobretudo porque tal linguagem é massivamente predominante na linguagem do dia a dia e na linguagem especializada e realiza papel relevante no processamento da linguagem de acordo com as hipóteses formuladas por Gibbs (1994).

No âmbito das práticas sociodiscursivas, a TMC pode contribuir para discussão a respeito de metáforas na condição de conceptualização das dinâmicas, das experiências sociais e das ideologias construídas e repercutidas pelos usuários da língua, sobretudo na construção de identidades sociais de gêneros, de acordo com os estudos realizados por Rodriguez (2009). Além 
disso, conforme assinalado, metáforas conceptuais, a exemplo das metáforas animais, se constituem em recurso cognitivo e primevo extremamente produtivo na conceptualização do ser humano e de seus comportamentos.

\title{
Animal metaphors and interactional implications
}

\begin{abstract}
The article focuses on implications of animal metaphors in everyday language taking into account the pragmatic approach to verbal metaphor based on the hypotheses of inexpressibility, of compactness and of vividness formulated by Gibbs (1994); and the discussion about the social role of animal metaphors as put forward by Rodriguez (2009). The paper is organized in three sections. In the first one, we discuss the role of verbal metaphors in human communication according to Gibbs (1994); in the second, the animal metaphor HUMAN IS ANIMAL; in the third, the relevance of animal metaphors in the comprehension and construal of genre and social identities (RODRIGUEZ, 2009). In connection with this concern, we analyze the animal metaphor 'perua' in the blog Saltimbanca and the site $\mathrm{Na}$ Casa da Gabi (At Gabi's House).
\end{abstract}

Keywords: Verbal metaphor. Animal metaphor. Gender and social identities. Everyday language. Verbal interactions.

\section{Referências}

A SALTIMBANCA: O direito de ser perua. Ou não. Disponível em: $<w w w$. soltandoosverbos.blogspot.com>. Acesso em: 8 mar. 2013.

CASA DA GABI: Ser-perua-é. Disponível em: <www.casadagabi.com>. Acesso em: 24 abr. 2013.

GIBBS, Raymond. The poetics of mind: Figurative thought, language, and understanding. New York: Cambridge University Press, 1994. 527 p.

KÖVECSES, Zoltán. Metaphor in culture: universality and variation. Nova York: Cambridge University Press, 2005.

KÖVECSES, Zoltán. Metaphor: a practical introduction. $2^{\text {nd }}$ ed. Oxford: Oxford University Press, 2010.

LAKOFF, George. The contemporary theory of metaphor. In: ORTONY, Andrew (Ed.). Metaphor and thought. Cambridge: Cambridge University Press, 1993. p. 202-251. 
LAKOFF, George; TURNER, Mark. More than cool reason: a field guide to poetic metaphor. Chicago: University of Chicago Press, 1989.

RODRIGUEZ, Irene Lopéz. Women, biches, chickens and vixens: animal metaphors for women in English and Spanish. Revista de Estudios Culturales de la Universitat Jaume I, v. 7, p. 77-10, 2009.

Recebido em 14/03/2016.

Aceito em 05/07/2016. 